\title{
mRNA overexpression of prolyl hydroxylase PHD3 is inversely related to nuclear grade in renal cell carcinoma
}

\author{
SPYRIDON KAMPANTAIS $^{1,2}$, VASILIKI KOTOULA ${ }^{3}$, ILIAS KOUNATIDIS ${ }^{4,5}$, IOANNIS VAKALOPOULOS ${ }^{1}$, \\ VICTORAS GOURVAS $^{6}$, STEFANIA LYMPERI ${ }^{7}$ and GEORGIOS DIMITRIADIS ${ }^{1}$
}

\author{
${ }^{1}$ 1st Department of Urology, Gennimatas General Hospital, Aristotle University of Thessaloniki, Thessaloniki 54635; \\ ${ }^{2}$ Department of Urology, Saint Luke's Private Hospital of Thessaloniki, Thessaloniki 55236; ${ }^{3}$ Department of Pathology, \\ Aristotle University of Thessaloniki, School of Health Sciences, Faculty of Medicine, Thessaloniki 54124, Greece; \\ ${ }^{4}$ Cell Biology, Development and Genetics Laboratory, Department of Biochemistry, University of Oxford, Oxford OX1 3QU; \\ ${ }^{5}$ Life and Sciences Department, Diamond Light Source, Harwell Science and Innovation Campus, \\ Didcot, Oxfordshire, Oxford OX11 0DE, UK; 'Private Pathology Lab 'Victoras Gourvas', \\ Thessaloniki 54624; ${ }^{7}$ Private Diagnostic Andrology Lab, Thessaloniki 54623, Greece
}

Received December 15, 2019; Accepted May 26, 2020

DOI:10.3892/mco.2020.2076

\begin{abstract}
The aim of the present study was to evaluate the relative mRNA expression levels of genes involved in the hypoxia inducible factor (HIF) signalling pathway in renal cell carcinoma (RCC) and to analyse their associations with clinicopathological parameters and survival outcomes. Reverse transcription-quantitative PCR was used to quantify the mRNA expression levels of HIF-1 $\alpha$, HIF- $2 \alpha$, prolyl hydroxylase (PHD)1, PHD2 and PHD3 in formalin-fixed paraffin-embedded (FFPE) tumour tissue samples from 41 patients with RCC, including 33 cases of clear cell RCC (ccRCC). FFPE samples of corresponding adjacent normal kidney tissues were used as a comparison. mRNA expression levels were analysed in regard to clinical parameters, histological type, stage, nuclear grade, cancer specific survival and overall survival. Compared with adjacent normal kidney tissue, HIF-1 $\alpha$ levels were lower in 16/33 ccRCC samples (48.48\%), while HIF-2 $\alpha$, PHD1 and PHD2 levels did not exhibit a specific expression pattern. By contrast, the PHD3 mRNA level was higher in 29/33 (87.87\%) of the tumour samples. HIF-1 $\alpha$ was positively associated with HIF-2 $\alpha$, PHD1 and PHD2. HIF-2 $\alpha$ levels were associated with PHD1, PHD2 and PHD3, while PHD3 was strongly associated with PHD2. PHD3 mRNA levels were inversely associated with nuclear grade $(\mathrm{P}=0.015)$. However, in univariate analysis, $\mathrm{PHD} 3$ was
\end{abstract}

Correspondence to: Dr Spyridon Kampantais, Department of Urology, Saint Luke's Private Hospital of Thessaloniki, Hlia Pileidi 20, Panorama, Thessaloniki 55236, Greece

E-mail: kabspir@hotmail.com

Key words: renal cell carcinoma, hypoxia, prolyl hydroxylase 3, Egl-9 family hypoxia inducible factor 3, hypoxia inducible factor, Fuhrman grade not associated with cancer-specific or overall survival rates. The present findings suggest an important involvement of PHD3 in ccRCC, since PHD3 mRNA expression was inversely associated with nuclear grade. However, PHD3 mRNA levels did not have an independent prognostic value. Further studies are required to investigate whether PHD3 could be used as either a therapeutic target or prognostic marker.

\section{Introduction}

Kidney cancer accounts for 2-3\% of all malignancies in adults and is the 12th most common cancer type worldwide $(1,2)$. Overall, $80-90 \%$ of kidney cancer cases develop in the renal parenchyma and are referred to as renal cell carcinoma (RCC) (3). There are three main RCC types: Clear cell RCC (ccRCC), papillary RCC (pRCC; type I and II) and chromophobe RCC (chRCC) (3). Unfortunately, 25\% of patients present with metastatic disease, while up to $40 \%$ of patients with locoregional RCC experience recurrence postoperatively, indicating the necessity to optimize treatment strategies for such patients. In addition to clinical and histological prognostic factors, numerous molecular factors have also been identified. These factors indicate which patients with localized RCC are at greater risk for recurrence, and which patients with metastatic disease are at risk of progression or death $(2,4)$.

The tumour microenvironment is characterized by decreased oxygen levels. Cancer cells, with their specific genetic and epigenetic mechanisms, have the ability to adapt to these hypoxic conditions $(5,6)$. This is partly achieved by regulation of gene products in response to hypoxia. A number of these hypoxia-regulated genes require the mediation of hypoxia inducible factors (HIFs), HIF- $1 \alpha$ and HIF-2 $\alpha$ (7). These two molecules heterodimerise with the aryl hydrocarbon nuclear translocator protein (also known as HIF- $\beta$ ), move into the nucleus and bind to DNA, leading to gene transcription activation of the responsive genes, which plays a pivotal role 
in angiogenesis (8). Under normoxia condition, HIF-1 $\alpha$ and HIF- $2 \alpha$ are continuously expressed and degraded. Degradation is mediated by the prolyl hydroxylases (PHDs). PHD1, PHD2 and PHD3 hydroxylate two proline residues (Pro-402/564) in the oxygen-dependent degradation domain of the HIF- $\alpha$ subunits. This allows the binding of HIF- $\alpha$ subunits to von Hippel-Lindau tumour suppressor (pVHL) to form a dimer that is degraded by the proteasome (Fig. 1) (9).

The present study investigated the possible involvement of the HIF/PHD pathway in RCC by evaluating HIF-1 $\alpha$, HIF-2 $\alpha$, PHD1, PHD2 and PHD3 mRNA expression levels using reverse transcription-quantitative PCR (RT-qPCR). The associations of these expression levels with clinicopathological parameters and survival outcomes were then analysed.

\section{Patients and methods}

Patients. The present study included 41 patients who underwent radical or partial nephrectomy for histopathologically verified RCC between December 2010 and September 2013. All patients were treated by the same surgical team at the $1 \mathrm{st}$ Department of Urology, Aristotle University of Thessaloniki, Greece. Written informed consent was obtained from every patient and the study protocol was approved by the Ethics Committee of Aristotle University of Thessaloniki.

Patients' clinical and pathological data were obtained prospectively, while follow-up and survival data were obtained by clinical appointments and/or telephone communication. Data included age, sex, tumour-node-metastasis (TNM) classification, Fuhrman grade, ECOG performance status, primary tumour size and presence of tumour necrosis. The RCC types were assessed according to the Heidelberg classification system (3). Tumour size was measured at the maximum diameter of the surgical specimen. Tumour stage and grade were determined by two independent pathologists, and controversies were resolved by consensus. Patients were evaluated from the time of diagnosis to the end of the study (June 2018). Overall survival (OS) time was defined as the time from nephrectomy to mortality from any cause.

Tissue processing and RNA template preparation. Hematoxylin and eosin (H\&E)-stained slides from formalin-fixed paraffin-embedded (FFPE) tissue blocks were reviewed for confirmation of diagnosis and abundance of tumour tissue. Tumour and matched normal tissues were used for the construction of low-density tissue microarrays (TMAs) with a manual arrayer (Model I; Beecher Instruments Inc.). TMAs contained two 1.5-mm sections per tumour (one from the front of the tumour and one from the centre of the tumour) and two sections from adjacent normal kidney tissue.

Total RNA was extracted from 8 - $\mu$ m TMA sections, one from adjacent normal tissue and one from tumour tissue per patient. The tumour section contained tissue from both the front and centre of the tumour. Tissue samples were transferred into a lysis buffer containing $500 \mu \mathrm{g} / \mathrm{ml}$ proteinase $\mathrm{K}$ for overnight lysis at $56^{\circ} \mathrm{C}$. Tissue lysates were then processed for total RNA extraction with TRIzol LS reagent (Invitrogen; Thermo Fisher Scientific, Inc.), according to the manufacturer's instructions. Subsequently, 4-5 $\mu \mathrm{g}$ total RNA was reverse transcribed into single-stranded complementary DNA
(cDNA) with random hexamers and SuperScript ${ }^{\circledR}$ III Reverse Transcriptase (Invitrogen; Thermo Fisher Scientific, Inc.), according to the manufacturer's instructions $(10,11)$.

$R T$ - $q P C R$. Relative mRNA expression was assessed by qPCR with the ABI 7900HT system under default conditions. B-glucuronidase (GUSB) was used as the endogenous reference for quantifying the relative mRNA expression levels (12). Reactions with $100 \mathrm{ng}$ template cDNA were performed in duplicate.

The following TaqMan-MGB probes (Thermo Fisher Scientific, Inc.) were used for the interrogated gene targets: HIF-1 $\alpha$ (Hs00153153_m1; NM_001243084.1; exons 4-5; 76 bp), HIF-2 $\alpha$ (Hs01026149_m1; NM_001430.4; exons 7-8; 70 bp), PHD1 (Hs00363196_m1; NM_053046.3; exons 5-6; 77 bp), PHD2 (Hs00254392_m1; NM_022051.2; exons 1-2; 70 bp), PHD3 (Hs00222966_m1; NM_022073.3; exons 3-4; 62 bp) and GUSB (Hs00939627_m1; NM_000181.3; exons 8 9; $96 \mathrm{bp}$ ). The data in parentheses refer to assay ID; Genbank reference; amplicon location; and size.

Relative mRNA expression of the target genes. Following amplification of all cDNA samples, the standard curves and the cycle threshold values of the samples $(\mathrm{Cq})$ were recorded. Then, the relative gene expression was calculated using the $2^{-\Delta \Delta \mathrm{Cq}}$ method. The corresponding values in matched normal samples were used a reference (Fig. S1) (13). Samples with an endogenous control $\mathrm{Cq} \geq 36$ were excluded. A 2 -fold increase $(\geq 2)$ or decrease $(\leq 0.5)$ in expression was considered biologically significant (for overexpression or downregulation, respectively), as previously published (14). Two samples for PHD1 and PHD3 and three samples for PHD2 were not eligible for analysis as the cDNA sample was inadequate or they had an endogenous control $\mathrm{Cq} \geq 36$.

Statistical analysis. Continuous variables are presented as the median and interquartile range (IQR), while certain categorical variables are presented as frequencies and percentages [n (\%)]. Fisher's exact test was used to analyse the associations between categorical variables. The non-parametric tests Mann-Whitney (for two groups) and Kruskal-Wallis (for multiple comparison) were used to compare the median values of continuous variables. In case of a significant result in Kruskal Wallis test multiple Mann-Whitney U Tests were applied using Bonferroni correction. Furthermore, Spearman's rank correlation $\left(\mathrm{R}_{\mathrm{s}}\right)$ coefficient was used to identify the correlation between continuous variables. Cox proportional hazard model was used to analyse the prognostic value of RNA levels in RCC. Test of normality was conducted using Shapiro-Wilk test, as well as histograms, P-P plots and Q-Q plots. $\mathrm{P}<0.05$ was considered to indicate a statistically significant difference. All reported P-values are two-sided. Data were analysed using SPSS 23.0 (IBM Corp.).

\section{Results}

Patients. Demographic data and clinicopathological characteristics of the patients are summarised in Table I. The mean age of the patients was $63.05 \pm 12.29$ years at the time of surgery and the mean follow-up time was $51.78 \pm 25.02$ months. 
Table I. Patient demographic data and clinicopathologic characteristics.

\begin{tabular}{|c|c|}
\hline Characteristic & Value \\
\hline Number of patients & 41 \\
\hline Body mass index $($ mean $\pm S D)$ & $28.26 \pm 4.86$ \\
\hline Age, years $($ mean $\pm S D)$ & $63.05 \pm 12.29(34-82)$ \\
\hline \multicolumn{2}{|l|}{ ECOG performance status (n, \%) } \\
\hline 0 & $30(73.2)$ \\
\hline 1 & $10(24.4)$ \\
\hline 2 & $1(02.4)$ \\
\hline \multicolumn{2}{|l|}{$\operatorname{Sex}(n, \%)$} \\
\hline Male & $25(61.0)$ \\
\hline Female & $16(39.0)$ \\
\hline Follow-up, months (mean \pm SD) & $51.78 \pm 25.02$ \\
\hline \multicolumn{2}{|l|}{ Smoking $(\mathrm{n}, \%)$} \\
\hline Yes & $14(34.1)$ \\
\hline Former & $16(39.0)$ \\
\hline No & $11(26.8)$ \\
\hline Tumour size, cm (mean $\pm \mathrm{SD})$ & $6.00 \pm 2.78$ \\
\hline \multicolumn{2}{|l|}{ Nephrectomy $(\mathrm{n}, \%)$} \\
\hline Partial & $5(12.2)$ \\
\hline Radical & $36(87.8)$ \\
\hline \multicolumn{2}{|l|}{ Tumour histology (n, \%) } \\
\hline $\mathrm{ccRCC}$ & $33(80.5)$ \\
\hline $\mathrm{pRCC}$ & $4(9.8)$ \\
\hline $\operatorname{chRCC}$ & $4(9.8)$ \\
\hline \multicolumn{2}{|l|}{ Tumour pathological stage (n, \%) } \\
\hline pT1a & $12(29.3)$ \\
\hline pT1b & $13(31.7)$ \\
\hline $\mathrm{pT} 2 \mathrm{a}$ & $3(7.3)$ \\
\hline $\mathrm{pT} 2 \mathrm{~b}$ & $3(7.3)$ \\
\hline pT3a & $10(24.4)$ \\
\hline \multicolumn{2}{|l|}{ Fuhrman nuclear grade RCC (n, \%) } \\
\hline 1 & $0(0.0)$ \\
\hline 2 & $12(29.3)$ \\
\hline 3 & $18(43.9)$ \\
\hline 4 & $11(26.8)$ \\
\hline \multicolumn{2}{|l|}{ Tumor necrosis $(\mathrm{n}, \%)$} \\
\hline Yes & $20(48.8)$ \\
\hline No & $21(51.2)$ \\
\hline
\end{tabular}

ccRCC, clear cell renal cell carcinoma; pRCC, papillary renal cell carcinoma; chRCC, chromophobe renal cell carcinoma.

Histology revealed 33 cases of ccRCC, 4 cases of pRCC and 4 cases of chRCC. At the end of follow-up, 13 patients had died, of which 7 were renal cancer-related. The median OS time was 64 months (IQR, 1-82).

$c c R C C$. The results of RT-qPCR analysis for the relative mRNA expression levels of the five genes in different tumours are presented in Fig. 2. PHD3 mRNA overexpression was

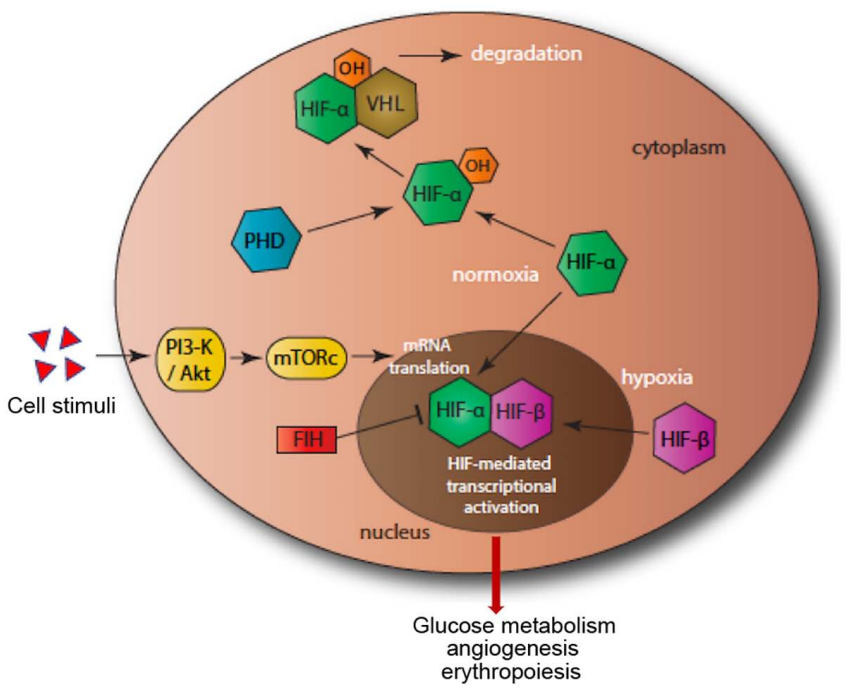

Figure 1. Hypoxia pathway. In normoxia, PHD (blue) hydroxylates HIF- $\alpha$ (green), which then binds to VHL, leading to proteosomal degradation. In hypoxia, HIF- $\alpha$ enters the nucleus, forms a dimer with HIF- $\beta$, which then binds to DNA, leading to gene transcription activation. A second pathway, that of PI3-K/Akt (yellow), initiates the mTOR and enhances the translation of HIF. FIH (red) adds a further level of control by reducing the transcriptional activity of HIF- $\alpha$. FIH, factor-inhibiting HIF; HIF- $\alpha$, hypoxia inducible factor $\alpha$; PHD, prolyl hydroxylase; VHL, von Hippel-Lindau tumor suppressor.

recorded in $87.87 \%(29 / 33)$ of the ccRCC samples. HIF-1 $\alpha$ levels were decreased in 16/33 (48.48\%) cases of ccRCC, while HIF-2 $\alpha$ did exhibit a specific pattern. In addition, PHD1 and PHD2 transcript levels were similar in the majority of patients.

HIF-1 $\alpha$ was positively correlated with HIF- $2 \alpha(\mathrm{P}=0.001)$, PHD1 $(\mathrm{P}<0.001)$ and PHD2 $(\mathrm{P}=0.035) . H I F-2 \alpha$ levels were significantly correlated with PHD1 $(\mathrm{P}<0.001)$, PHD2 $(\mathrm{P}<0.001)$ and PHD3 $(\mathrm{P}<0.001)$, while PHD3 was significantly correlated with PHD2 $\mathrm{P}<0.001)$.

chRCC and $p R C C$. PHD3 overexpression was observed in 2/4 of the chRCC cases and in 3/4 of the pRCC cases (Fig. 2). Relative mRNA expression levels of interrogated genes in different renal cell carcinomas are shown in Table II.

Correlation of HIF-1a, HIF-2a, PHD1, PHD2 and PHD3 expression levels with clinical parameters of ccRCC samples. Relative mRNA expression levels of the analysed genes were not associated with the majority of the clinical parameters evaluated, including age, BMI, smoking history, performance status, red blood cell count, haemoglobin, platelet count, calcium, LDH and creatinine. The only positive correlation identified was between PHD3 expression and pre-operative haemoglobin level $(\mathrm{P}=0.032)$.

With regard to pathological parameters, PHD3 expression levels were inversely associated with Fuhrman grade $(\mathrm{P}=0.015$; Fig. 3). The median relative expression level of PHD3 mRNA was 43.51 (31.93-123.09) in grade II tumours, 41.53 (7.89-60.00) in grade III tumours and significantly lower in grade IV tumours, which had a relative expression level of 6.29 (3.43-24.59). No other association was recorded between mRNA expression levels and tumour stage, presence of necrotic or presence of sarcomatous elements. 
Table II. Relative mRNA expression levels of genes of interest.

\begin{tabular}{lccc}
\hline Gene & Clear cell & Papillary & Chromophobe \\
\hline HIF1a & $0.48(0.28-0.95)$ & $3.79(0.24-35.15)$ & $0.17(0.07-0.26)$ \\
HIF2a & $1.17(0.29-1.96)$ & $0.36(0.16-3.26)$ & $0.42(0.12-0.73)$ \\
PHD1 & $0.65(0.43-1.19)$ & $0.63(0.12-50.20)$ & $0.25(0.05-0.46)$ \\
PHD2 & $1.34(0.86-1.99)$ & $0.56(0.26-9.89)$ & $0.48(0.12-0.83)$ \\
PHD3 & $34.80(6.69-58.19)$ & $59.41(2.26-197.92)$ & $3.38(2.48-4.30)$
\end{tabular}

Data are presented as the median and interquartile range. HIF, hypoxia inducible factor; PHD, prolyl hydroxylase.

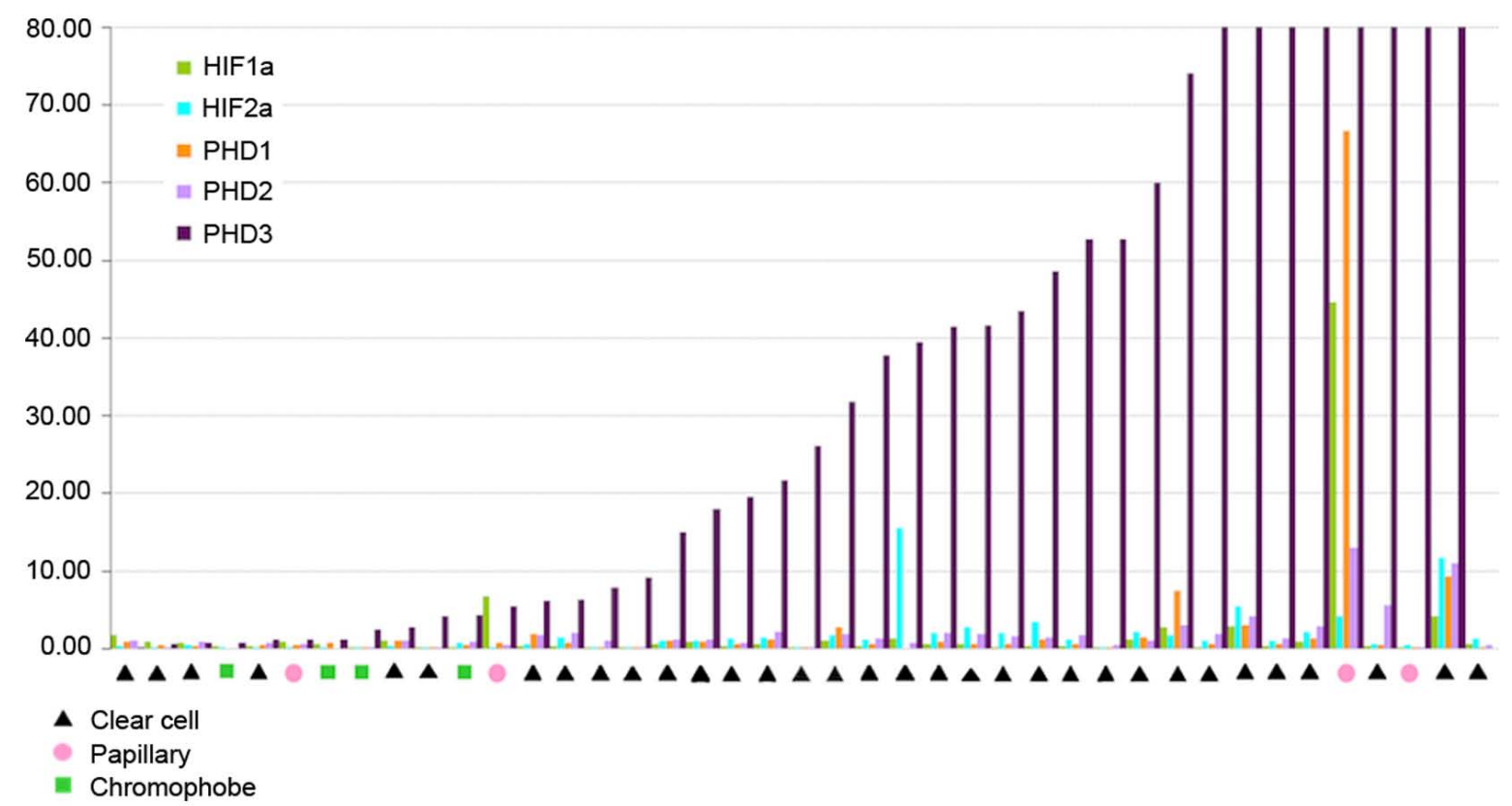

Figure 2. Cumulative results of the reverse transcription-quantitative PCR analysis of the relative mRNA expression of the five genes. Overexpression of PHD3 (purple colour) was observed in 29/33 clear cell renal cell carcinoma cases. HIF, hypoxia inducible factor; PHD, prolyl hydroxylase.

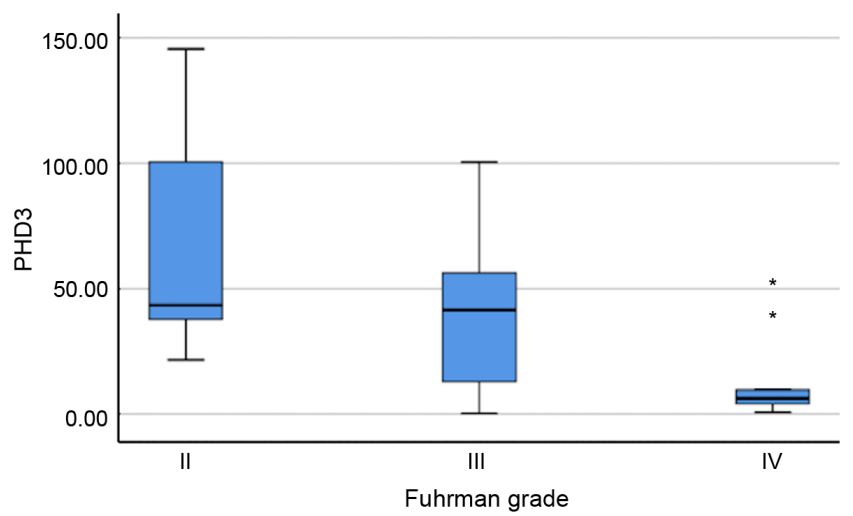

Figure 3. PHD3 expression levels and Fuhrman grade $(\mathrm{P}=0.015$; Kruskal-Wallis test). *Extreme exceptions. PHD, prolyl hydroxylase 3.

All the aforementioned clinical and pathological variables were evaluated for their prognostic value (Table III). Of these, stage, grade, serum LDH, age and PHD2 mRNA expression demonstrated a statistically significant correlation with OS in the univariate analysis.

\section{Discussion}

A key feature in the development of ccRCC, is the inactivation of the tumour suppressor pVHL, which leads to activation of the HIF pathway. Important regulators of HIF- $\alpha$ are PHD1, PHD2 and PHD3, which mediate the degradation of HIF-1 $\alpha$ and HIF-2 $\alpha$. PHD3 has been shown to be the critical isoform that demonstrates the most robust induction of expression under hypoxia, while it is inactive in normoxic conditions $(15,16)$. Aside from its HIF-dependent functions, PHD3 has been suggested to have the widest range of non-HIF targets and downstream effectors (17). Recently, Högel et al (18) demonstrated that PHD3 maintains cell growth and enhances cell cycle progression in renal cancer by decreasing the stability of p27. Additionally, there is a crucial involvement of PHD3 in the maintenance of key cellular functions, including glycolysis and protein synthesis, in ccRCC. PHD3 depletion significantly affects cellular processes associated with glucose metabolism, post-transcriptional modification and translation regulation in ccRCC cells (19).

In ccRCC, PHD3 is highly expressed. Sato et al (20) reported that PHD3 is frequently overexpressed in RCC 
Table III. Univariate Cox regression analysis for overall survival.

\begin{tabular}{llll}
\hline Factor & HR & 95\% CI & P-value \\
\hline HIF1a & 0.39 & $0.10-1.44$ & 0.158 \\
HIF2a & 0.98 & $0.81-1.20$ & 0.863 \\
PHD1 & 0.56 & $0.22-1.48$ & 0.244 \\
PHD2 & 0.46 & $0.22-0.99$ & 0.049 \\
PHD3 & 0.99 & $0.97-1.01$ & 0.449 \\
Stage & 2.45 & $1.32-4.54$ & 0.004 \\
Grade & 4.41 & $1.73-11.25$ & 0.002 \\
LDH & 1.01 & $1.00-1.01$ & 0.042 \\
Calcium & 0.87 & $0.41-1.82$ & 0.711 \\
PLT & 1.00 & $1.00-1.01$ & 0.362 \\
Hb & 0.92 & $0.70-1.20$ & 0.537 \\
RBC & 1.00 & $1.00-1.00$ & 0.568 \\
ECOG performance status & 2.13 & $0.88-5.15$ & 0.093 \\
Age & 1.06 & $1.00-1.18$ & 0.041 \\
Smoking history & 2.12 & $0.96-4.66$ & 0.062 \\
\hline
\end{tabular}

HR, hazard ratio; CI, confidence interval; LDH, lactate dehydrogenase; Hb, hemoglobin; RBC, red blood cells; ECOG, Eastern Cooperative Oncology Group; HIF, hypoxia inducible factor; PHD, prolyl hydroxylase.

tissue and demonstrated its usefulness as a novel tumour antigen in immunotherapy for RCC (20). In this previous study, expression of PHD3 was quantified by RT-qPCR and immunostaining of RCC cell lines and primary RCC tissues. Increased PHD3 mRNA expression levels were observed in tumour tissues in $13 / 15(87 \%)$ cases, which is similar to the present result of $87.87 \%$. The previous study determined that PHD3 is selectively expressed in cancerous tissue but not in non-cancerous tissue (20).

Tanaka et al (21) further confirmed the aforementioned findings, demonstrating with RT-qPCR that PHD3 was overexpressed in 21/22 (95.4\%) of the RCC tumour specimens (21). However, a notable finding of their study was that PHD3 overexpression at the mRNA level was equally observed in RCC tissues, with no associations with mutations or epigenetic modifications of the VHL gene, which was also the case in chromophobe and spindle cell carcinoma (21). An alternative mechanism that could potentially explain this phenomenon is that tissue hypoxia may induce PHD3 expression, as the catalytic activity of PHD3 is oxygen-dependent, and hypoxia may induce accumulation of unhydroxylated and undegraded HIF proteins (22).

Tanaka et al (23) also studied the mechanism and role of PHD3 expression in RCC using RCC cell lines with and without VHL gene mutation, as well as RCC tissues. High mRNA expression levels of PHD3 were observed in both VHL-mutant cell lines and VHL-wild-type cell lines. The aforementioned increased expression levels were highly associated with activation of the PI3K/Akt pathway in the VHL-wild-type RCC cell lines, independent of HIF proteins (Fig. 1). On the other hand, in the VHL-mutant RCC cell lines, PHD3 expression was more strongly associated with HIF accumulation, likely due to inactive VHL. The previous study also examined PHD3 expression by immunohistochemistry in 116 patients with ccRCC who underwent radical or partial nephrectomy between 2001 and 2009, and correlation analysis was performed between the expression levels and prognosis. PHD3-positive cells were observed in 82 of the 116 cases (70.7\%), with the 5-year recurrence-free survival to be statistically improved in patients with PHD3-positive tumours compared with those with PHD3-negative tumours $(\mathrm{P}=0.003)$. However, there was no significant difference in the cancer-specific survival between the two groups (23).

The present mRNA expression data of five main hypoxia genes in 33 cases are in agreement with the previous studies. PHD3 mRNA expression levels in ccRCC were found to be significantly high in comparison with other genes related to the tumour hypoxia pathway.

In the ccRCC samples analysed in the current study, PHD3 mRNA overexpression was inversely associated with nuclear grade. To the best of our knowledge, this is the first study to identify a correlation between PHD3 expression level and the aggressiveness of tumour cells, suggesting a crucial involvement of PHD3 in ccRCC. Kroeze et al (24) studied the same pathway by immunohistochemistry of a tissue microarray containing tumours from 100 patients who underwent nephrectomy for ccRCC. Significant correlations between Fuhrman grade and the expression levels of all three PHD proteins were identified (PHD1, $\mathrm{P}=0.024$; PHD2, $\mathrm{P}=0.0067$; $\mathrm{PHD} 3, \mathrm{P}=0.0012$ ) (24). This correlation was not confirmed for PHD1 and PHD2 in the present study sample. However, both studies did not record any association of PHD3 expression with survival outcomes. This may be due to the small number of patients included in the current study. In the study of Kroeze et al, nuclear factor-inhibiting HIF (FIH) expression in the primary tumour exhibited a significant independent prognostic value for patients with ccRCC in multivariate analysis, suggesting that FIH may have 
an important function as one of the final checks of HIF- $\alpha$ transcriptional activity.

It is notable, that in ccRCC, the HIF pathway is upregulated by inactivation of the pVHL tumour suppressor (25). Both HIF-1 $\alpha$ and HIF-2 $\alpha$ are important regulators of angiogenesis and cell proliferation. In ccRCC, HIF-2 $\alpha$ has been reported to be involved in tumorigenesis and tumour progression (24). Recent data from Chen et al (26) and Wallace et al (27) demonstrates that HIF-2 $\alpha$ can be specifically targeted by small molecule antagonists, which may offer a novel approach for treating RCC. In the present study, PHD3 mRNA levels were significantly associated with HIF- $2 \alpha$ levels and inversely associated with Fuhrman grade; these findings may indicate that PHD3 potentially serves a negative feedback role to decrease HIF- $2 \alpha$ activity, representing a possible therapeutic target in controlling HIF- $2 \alpha$. However, further experiments are necessary to confirm the suggested correlation between PHD3 and HIF-2 $\alpha$.

Finally, it would be negligent not to mention that the present study has some limitations. The mutation status of the VHL gene was not evaluated since extensive previous literature has reported the absence of any correlation between VHL gene mutations and clinicopathological parameters or survival of patients $(21,24)$. Additionally, the number of patients included in the present study was small, but similar to other studies in the field, which is expected given the low incidence of renal carcinoma in the general population. However, the current study presents, to the best of our knowledge, the largest cohort for the evaluation of mRNA expression levels of five main hypoxia-related genes by RT-qPCR and subsequent analyses.

In conclusion, the present study demonstrated that PHD3 may play an important role in the valuable host molecular adaptation that occurs during oxidative stress in ccRCC. Further studies are required to validate the present results in view of employing PHD3 as a prognostic and/or therapeutic target for ccRCC.

\section{Acknowledgements}

The authors would like to thank Mrs. Aimilia Daskalaki (Department of Pathology, Aristotle University of Thessaloniki, School of Health Sciences, Faculty of Medicine, Thessaloniki 54124, Greece) for providing support for reverse transcription-quantitative PCR.

\section{Funding}

The present study was supported by the Hellenic Urological Association.

\section{Availability of data and materials}

The datasets used and/or analyzed during the current study are available from the corresponding author on reasonable request.

\section{Authors' contributions}

SK, VK, VG and GD conceived and designed the study. SK enrolled the patients, collected and interpreted patient data and wrote the manuscript. VK supervised tissue processing, RNA template preparation and RT-qPCR. VK and IV provided experimental and clinical advice. VG contributed to the pathological review. SK, IK, IV and SL analysed and interpreted the clinical and molecular data. IV and SL helped to draft the manuscript. GD and VK supervised the study and gave final approval of the version to be published. All authors read and approved the final manuscript.

\section{Ethics approval and consent to participate}

The present study was approved by the Institutional Review Board of Gennimatas General Hospital, Aristotle University of Thessaloniki, Greece (approval no. 18061/24-12-2013). Written informed consent was obtained from all patients prior to enrolment.

\section{Patient consent for publication}

Not applicable.

\section{Competing interests}

The authors declare that they have no competing interests.

\section{References}

1. Jemal A, Siegel R, Xu J and Ward E: Cancer statistics, 2010. CA Cancer J Clin 60: 277-300, 2010.

2. Sun M, Marconi L, Eisen T, Escudier B, Giles RH, Haas NB, Harshman LC, Quinn DI, Larkin J, Pal SK, et al: Adjuvant vascular endothelial growth factor-targeted therapy in renal cell carcinoma: A systematic review and pooled analysis. Eur Urol 74: 611-620, 2018.

3. Kovacs G, Akhtar M, Beckwith BJ, Bugert P, Cooper CS, Delahunt B, Eble JN, Fleming S, Ljungberg B, Medeiros LJ, et al: The Heidelberg classification of renal cell tumours. J Pathol 183: 131-133, 1997.

4. Lane BR and Kattan MW: Prognostic models and algorithms in renal cell carcinoma. Urol Clin North Am 35: 613-625; vii, 2008.

5. Kimbro KS and Simons JW: Hypoxia-inducible factor-1 in human breast and prostate cancer. Endocr Relat Cancer 13: 739-749, 2006

6. Vaupel P, Kelleher DK and Höckel M: Oxygen status of malignant tumors: Pathogenesis of hypoxia and significance for tumor therapy. Semin Oncol 28 (Suppl 8): 29-35, 2001.

7. Maxwell PH, Wiesener MS, Chang GW, Clifford SC, Vaux EC, Cockman ME, Wykoff CC, Pugh CW, Maher ER and Ratcliffe PJ: The tumour suppressor protein VHL targets hypoxia-inducible factors for oxygen-dependent proteolysis. Nature 399: 271-275, 1999.

8. Mandriota SJ, Turner KJ, Davies DR, Murray PG, Morgan NV, Sowter HM, Wykoff CC, Maher ER, Harris AL, Ratcliffe PJ and Maxwell PH: HIF activation identifies early lesions in VHL kidneys: Evidence for site-specific tumor suppressor function in the nephron. Cancer Cell 1: 459-468, 2002.

9. De Luise M, Girolimetti G, Okere B, Porcelli AM, Kurelac I and Gasparre G: Molecular and metabolic features of oncocytomas: Seeking the blueprints of indolent cancers. Biochim Biophys Acta Bioenerg 1858: 591-601, 2017.

10. Gerard GF, D'Alessio JM, Kotewicz ML and Noon MC: Influence on stability in Escherichia coli of the carboxy-terminal structure of cloned Moloney murine leukemia virus reverse transcriptase. DNA 5: 271-279, 1986.

11. Kotewicz ML, D'Alessio JM, Driftmier KM, Blodgett KP and Gerard GF: Cloning and overexpression of Moloney murine leukemia virus reverse transcriptase in escherichia coli. Gene 35: 249-258, 1985.

12. Marathe SV and McEwen JE: Vectors with the gus reporter gene for identifying and quantitating promoter regions in Saccharomyces cerevisiae. Gene 154: 105-107, 1995. 
13. Schmittgen TD and Livak KJ: Analyzing real-time PCR data by the comparative C(T) method. Nat Protoc 3: 1101-1108, 2008.

14. Gourvas V, Sifakis S, Dalpa E, Soulitzis N, Koukoura O and Spandidos DA: Reduced placental prolyl hydroxylase $3 \mathrm{mRNA}$ expression in pregnancies affected by fetal growth restriction. BJOG 117: 1635-1642, 2010.

15. Aprelikova O, Chandramouli GV, Wood M, Vasselli JR, Riss J, Maranchie JK, Linehan WM and Barrett JC: Regulation of HIF prolyl hydroxylases by hypoxia-inducible factors. J Cell Biochem 92: 491-501, 2004.

16. Rantanen K, Pursiheimo JP, Hogel H, Miikkulainen P, Sundstrom J and Jaakkola PM: p62/SQSTM1 regulates cellular oxygen sensing by attenuating PHD3 activity through aggregate sequestration and enhanced degradation. J Cell Sci 126: 1144-1154, 2013.

17. Jaakkola PM and Rantanen K: The regulation, localization, and functions of oxygen-sensing prolyl hydroxylase PHD3. Biol Chem 394: 449-457, 2013.

18. Högel H, Miikkulainen P, Bino L and Jaakkola PM: Hypoxia inducible prolyl hydroxylase PHD3 maintains carcinoma cell growth by decreasing the stability of p27. Mol Cancer 14: 143, 2015.

19. Miikkulainen P, Hogel H, Rantanen K, Suomi T, Kouvonen P, Elo LL and Jaakkola PM: HIF prolyl hydroxylase PHD3 regulates translational machinery and glucose metabolism in clear cell renal cell carcinoma. Cancer Metab 5: 5, 2017.

20. Sato E, Torigoe T, Hirohashi Y, Kitamura H, Tanaka T, Honma I, Asanuma H, Harada K, Takasu H, Masumori N, et al: Identification of an immunogenic CTL epitope of HIFPH3 for immunotherapy of renal cell carcinoma. Clin Cancer Res 14: 6916-6923, 2008.

21. Tanaka T, Kitamura H, Torigoe T, Hirohashi Y, Sato E, Masumori N, Sato N and Tsukamoto T: Autoantibody against hypoxia-inducible factor prolyl hydroxylase-3 is a potential serological marker for renal cell carcinoma. J Cancer Res Clin Oncol 137: 789-794, 2011.
22. Appelhoff RJ, Tian YM, Raval RR, Turley H, Harris AL, Pugh CW, Ratcliffe PJ and Gleadle JM: Differential function of the prolyl hydroxylases PHD1, PHD2, and PHD3 in the regulation of hypoxia-inducible factor. J Biol Chem 279: 38458-38465, 2004.

23. Tanaka T, Torigoe T, Hirohashi Y, Sato E, Honma I, Kitamura H, Masumori N, Tsukamoto T and Sato N: Hypoxia-inducible factor (HIF)-independent expression mechanism and novel function of HIF prolyl hydroxylase-3 in renal cell carcinoma. J Cancer Res Clin Oncol 140: 503-513, 2014.

24. Kroeze SG, Vermaat JS, van Brussel A, van Melick HH, Voest EE, Jonges TG, van Diest PJ, Hinrichs J, Bosch JL and Jans JJ: Expression of nuclear FIH independently predicts overall survival of clear cell renal cell carcinoma patients. Eur J Cancer 46: 3375-3382, 2010.

25. Salama R, Masson N, Simpson P, Sciesielski LK, Sun M, Tian YM, Ratcliffe PJ and Mole DR: Heterogeneous effects of direct hypoxia pathway activation in kidney cancer. PLoS One 10: e0134645, 2015.

26. Chen W, Hill H, Christie A, Kim MS, Holloman E, Pavia-Jimenez A, Homayoun F, Ma Y, Patel N, Yell P, et al: Targeting renal cell carcinoma with a HIF-2 antagonist. Nature 539: 112-117, 2016

27. Wallace EM, Rizzi JP, Han G, When PM, Cao Z, Du X, Cheng T, Czerwinski RM, Dixon DD, Goggin BS, et al: A small-molecule antagonist of HIF2 $\alpha$ is efficacious in preclinical models of renal cell carcinoma. Cancer Res 76: 5491-5500, 2016.

(7) $\odot$ This work is licensed under a Creative Commons Attribution-NonCommercial-NoDerivatives 4.0 International (CC BY-NC-ND 4.0) License. 